\title{
Development of an Inspection Platform and a Suite of Sensors for Assessing Corrosion and Mechanical Damage on Unpiggable Transmission Mains
}

\author{
Quarterly Report
}

For the period of

April 1, 2003 to June 30, 2003

Dr. George C. Vradis

Consultant to the RD\&D Director

Northeast Gas Association

\author{
Bill Leary \\ Project Manager \\ Foster-Miller, Inc.
}

July 2003

DOE Award Number: DE-FC26-02NT41645

\author{
Northeast Gas Association \\ 1515 Broadway, $43^{\text {rd }}$ Floor \\ New York, NY 10036 \\ Foster-Miller, Inc. \\ 350 Second Ave. \\ Waltham, MA 02451-1196
}




\section{DISCLAIMER}

"This report was prepared as an account of work sponsored by an agency of the United States Government. Neither the United States Government nor any agency thereof, nor any of their employees, makes any warranty, express or emplied, or assumes any legal liability or responsibility for the accuracy, completeness, or usefulness of any information, apparatus, product, or process disclosed, or represents that its use would not infringe privately owned rights. Reference herein to any specific commercial produc, process, or service by trade name, trademark, manufacturer, or otherwise does not necessarily constitute or imply its endorsement, recommendation, or favoring by the United States Government or any agency thereof. The views and opinions of the authors expressed herein do not necessarily state or reflect those of the United States Government or any agency thereof." 


\begin{abstract}
This development program is a joint effort among the Northeast Gas Association (formerly New York Gas Group), Foster-Miller, Inc., and the US Department of Energy (DOE) through the National Energy Technology Laboratory (NETL). The DOE's contribution to this project is $\$ 572,525$ out of a total of $\$ 772,525$.
\end{abstract}

The present report summarizes the accomplishments of the project during its third threemonth period (from April 2003 through June 2003). The project was initiated with delay in February 2003 due to contractual issues that emerged between NGA and Foster-Miller, Inc. The two organizations are working diligently to maintain the program's pace and expect to complete it in time.

The efforts of the project focused during this period in finalizing the assessment of the tether technology, which is intended to be used as the means of communication between robot and operator. Results indicate that the tether is a viable option under certain pipeline operating conditions, but not all. Concerns also exist regarding the abrasion resistance of the tether, this issue being the last studied. Substantial work was also conducted on the design of the robotic platform, which has progressed very well. Finally, work on the MFL sensor, able to negotiate all pipeline obstacles (including plug valves), was initiated by PII following the successful completion of the subcontract negotiations between Foster-Miller and PII. The sensor design is at this point the critical path in the project's timetable. 


\section{TABLE OF CONTENTS}

$\begin{array}{ll}\text { Abstract } & 3\end{array}$

Table of Contents

Executive Summary

Introduction

Experimental

9

Project Status by Task

20

Results and Discussion

Conclusions

22

References

23 


\section{EXECUTIVE SUMMARY}

The PII subcontract was finally signed in early June, 2003. A kickoff and MFL sensor brainstorm meeting was held during the week of June $23^{\text {rd }}$. The workflow has been revised based on PII's late entry into the program. The program is expected to be completed in December 2003, with the design effort scheduled to be completed the first week in November. Foster-Miller will complete the kinematics testing in the mockup by the first week of August, finalizing the design requirements for the platform, and will then work at a reduced pace to preserve program funds and allow PII to catch-up. Foster-Miller will return to the original program pace in September, with the design of the tractors, modules, and the MFL sensor (with actuation mechanism) continuing through mid-October. The design integration portion of the program will commence in mid-October and carry through the first week in November. During this period, all sub-assemblies will be integrated into a single platform design. The draft final report will be completed by December 1 .

At the end of this reporting period the project was progressing well. The tether assessment

effort is nearly complete. The robot design has progressed well, while conceptual MFL sensor design was initiated. 


\section{INTRODUCTION}

With the recent advances in robotics and sensor technology, and the occurrence a few unfortunate pipeline accidents, the Office of Pipeline Safety (OPS) of the US Department of Transportation has endorsed the concept that all oil and gas transmission pipelines should be capable of 100 percent inspection. This can be accomplished through the elimination of pipeline obstacles that would allow for pigging, or through the development of innovative inspection technologies, hydro testing, or use of direct assessment techniques. Problems arise when the piping network is older and/or constructed without pigging as a design consideration. This is the situation with countless miles of transmission pipelines owned and operated by local gas distribution utilities. There are many physical "obstacles" in the piping network that makes pigging impossible. The most intractable of these obstacles include:

- Bends/elbows with bend radius less than 1.5 D. This is a very common obstruction.

- Mitered joints/elbows greater than $10 \mathrm{deg}$. This is an obstacle found in older systems.

- Back to back combinations of bends/joints. Commonly found in tightly spaced areas.

- Reduced port valves. This includes valves with ports smaller in diameter than the pipeline. This is also a very common obstacle.

- Reduction/expansion in pipe diameter greater than 2 in.

- Unbarred branch connections. Pigs are not designed to turn down branch lines, and therefore, branch lines must be barred to prevent the nose of the pig from crashing into the lateral and jamming itself in place.

The Gas Research Institute in a report issued in 1995 (entitled "In-Line Inspection of Unpiggable Natural Gas Pipelines") noted that the cost to replace just two of the most common obstacles would be substantial, costing over $\$ 3$ billion. Therefore, the development of tools to inspect un-piggable transmission and/or distribution pipelines presents a both a formidable technical challenge as well as a significant financial incentive to the gas industry. The adaptation of current pigging technology may not be viable given the geometric challenges of existing interstate and utility owned pipelines. External direct assessment techniques have not been shown to be universally adequate, accurate or cost-effective. Use of an innovative robotic approach would apparently be dictated. 
The inspection of un-piggable gas transmission and distribution pipelines requires the innovative marriage of a highly adaptable/agile robotic platform with advanced sensor technologies operating as an autonomous or semi-autonomous inspection system. The work being conducted under this program is based on a robotic platform that is train-like in nature ,as shown in the figure below, and is based on Foster-Miller's Pipeline Inspection System (PipeMouse) developed in early to mid 1990's. Both front and rear tractors propel the train in the forward and reverse directions inside the pipeline. Like a train, the platform includes additional "cars" to carry the required payloads. The cars are used for various purposes including the installation and positioning of sensor modules, the power supply, data acquisition/storage, location/position devices and onboard micro-processors/electronics. The onboard intelligence gives the platform the benefit of an engineer steering the train through complicated pipe geometry. The system includes launching and retrieval stations that are similar to that used for conventional pigging systems, but much simpler in design and operation.

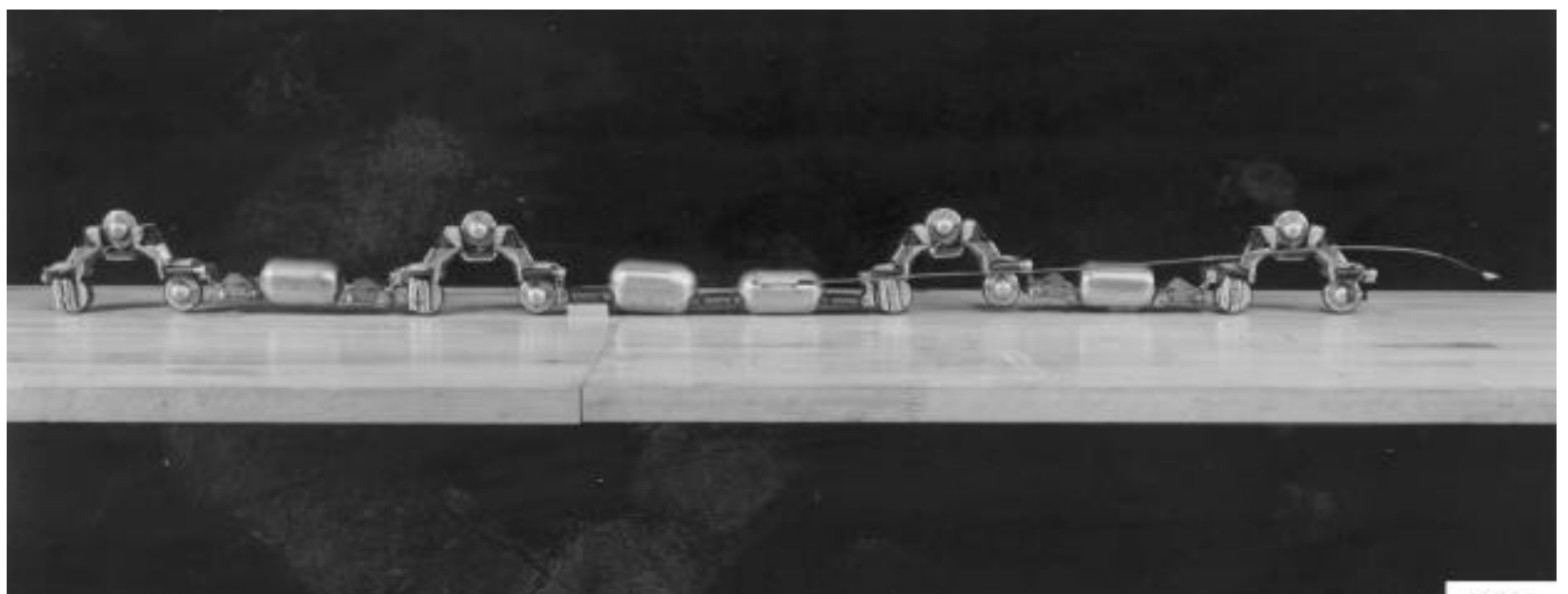

The Pipe Mouse was built to a strict set of performance criteria appropriate for low-pressure gas distribution networks. The Mouse was designed to be highly mobile and agile, had the ability to travel long distances from the entry point and steer down branch line of pipe tees, negotiate mitered (zero degrees) elbows, navigate in both the horizontal and vertical planes, pass through partial section valves, and adapt, by a factor of two, to changes in pipe diameter. 
These same types of obstacles create problems for inspecting un-piggable transmission mains.

PII North America (a subcontractor for this project) has extensive experience designing and working with sensors based on ultrasonics, electromagnetism, eddy-currents and optical methods. For this program, sensor development will be considerably more challenging than for conventional pigging due to the greater variance of pipe diameter and the more difficult obstacles encountered in un-piggable pipelines. The ability to actively expand and retract the onboard sensor will be needed, not just for obstacle avoidance, but to allow upstream (reverse direction) travel.

The robot will be controlled via a fiberoptic tether system, which will be analyzed, designed, and tested as part of this project. The tether is expected to provide sufficient range for the robot to inspect a substantial length of the pipe without the need of many expensive tapings of the pipeline

To power the computer, sensors, data acquisition and drive wheels, some form of energy storage and electrical power supply is required. Of all the various possibilities (e.g., batteries, fuel cells, ultra-capacitors, flywheels, etc.), the battery approach is clearly the simplest, safest and most reliable. To minimize the number of launch and retrieval stations, the batteries should have maximum energy density. The modular platform concept has an advantage in that battery "cars" can be added as needed, up to the length of the launch tube. Certain obstacles (e.g., mitered corners) also impose a length constraint. Different battery and charging modules may also be swapped in and out based on the range requirement, power and availability of recharging stations.

The anticipated benefits derived from the use of this platform include the following:

- Ability to inspect otherwise inaccessible pipelines (transmission and distribution).

- Cost savings from not having to remove pipeline obstacles for conventional pigs.

- Inspection cost much lower $(\$ /$ mile) than direct assessment or hydro testing.

- A more versatile platform capable of performing a variety of inspection services. 


\section{EXPERIMENTAL}

During the period of April 1, 2003 to June 30, 2003 work on the project was initiated.

\section{Task 1: Program Management}

An updated workflow chart was developed following the kickoff meeting between FosterMiller and PII, as shown below (Figure 1).

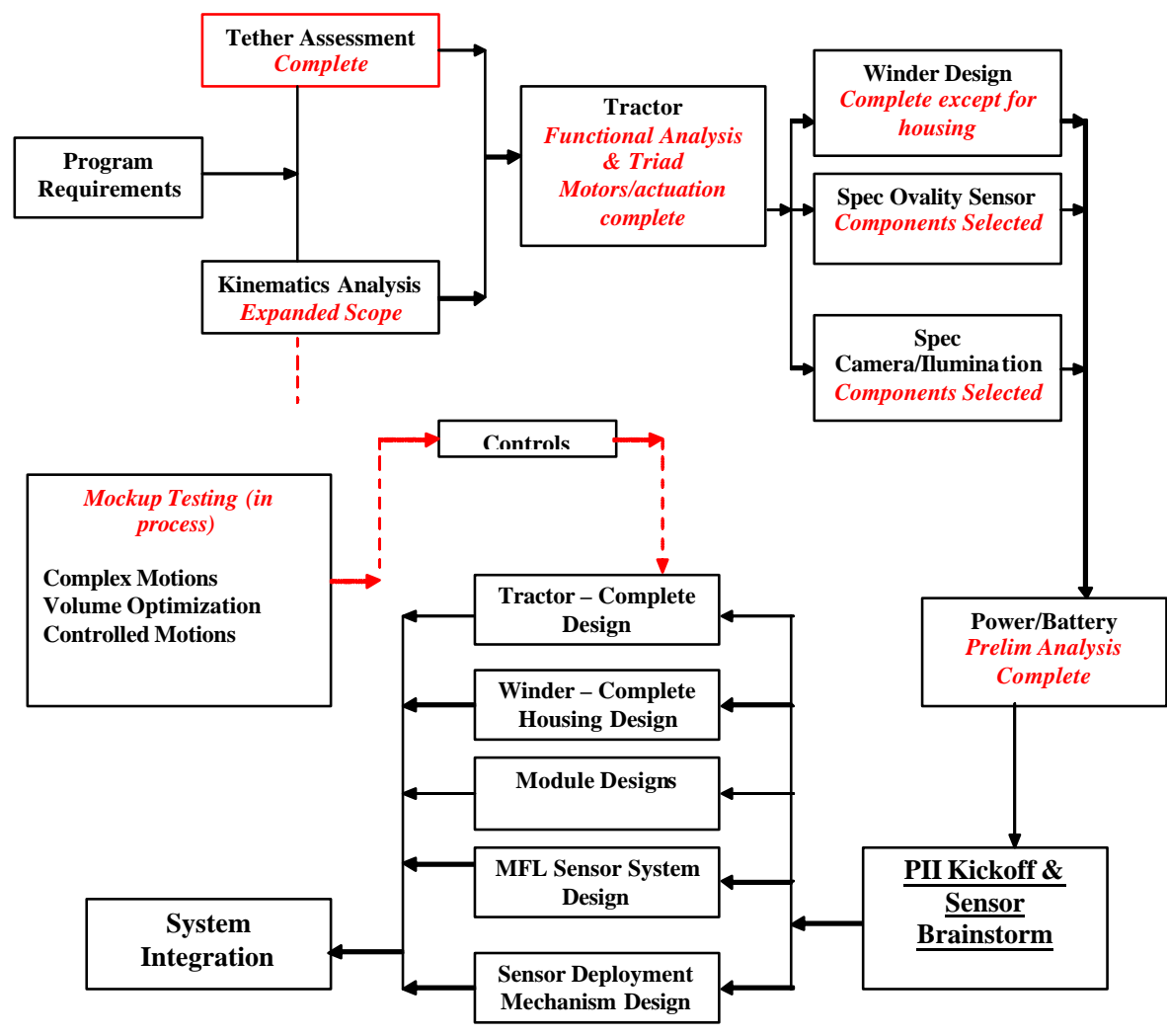

Figure 1. Revised workflow 


\section{Task 2: Mechanical Design: Robotic Design and Sensor Module}

\section{Task 2.1. Robotic Platform}

\section{Task 2.1.1 System Engineering}

\section{Task 2.1.1.1 Kinematic Analysis}

The kinematics/mockup testing portion of the program has expanded in scope. We now believe that a higher priority (and more resources than originally budgeted) needs to be placed on mockup testing to better understand the design challenge of producing a platform that can adjust in size to accommodate multiple pipe sizes with back-to-back out-of-plane bends (increased platform portability). In order for the adjustable link arm concept to be adequately tested (back-to-back out-of-plane bends), the telescoping arms of each link arm were modified to simplify adjustment. Timing gears were added to each triad to synchronize the angular motion of each link arm of the triad. These changes will permit better control of the mocked-up tractor when manually moving it within the pipeline. To better stabilize the pipe during testing, supports were added to the outside of the pipe. Access holes were placed in strategic locations to facilitate the movement of the mocked-up platform through each obstacle in the pipeline.

The goal of the kinematics/mockup testing is to establish the design requirements for the platform. These include:

- Triad link lengths, shapes, and mechanical means for active adjustment

- Triad max and min wheelbases

- Linkage/joint configuration and placement, force requirements (tension, compression, torque), and active or passive control requirements

- Required motions and timing to clear obstacles

- Load sharing requirements between front and rear tractor

- Overall volume requirements (platform and modules) 
- Control sensor requirements

\section{Task 2.1.1.2: Brainstorming Session}

A brainstoring session was held between Foster-Miller and PII on June 24, 2003 to develop concepts and ideas related to the integration of the sensor technology into the robotic platform.

\section{Task 2.1.1.3: Tractor Design}

As presented in the last report, drive systems were selected for the wheel drive, wheel steering, and wheel clamping systems. Their selection was based on the power required to overcome flow drag under max flow conditions of 1,000 psig and $75 \mathrm{ft} / \mathrm{s}$, resulting in a drive force of $2000 \mathrm{lb}$ with MFL on, and $1200 \mathrm{lb}$ with MFL off. It has since been decided, based on tether flow drag limitations, that the system will be designed for the nominal conditions of 350 psig and $20 \mathrm{ft} / \mathrm{s}$. Under the nominal conditions, the flow drag forces will be insignificant, except for those infrequent times when passing through plug valve. Power consumption will chiefly be a function of sensor drag. As discussed below, PII will conduct experiments to determine sensor flow drag (and thus power required to pull the sensor).

In order that we may better define the platform's power requirements, a template for a typical 2.5 mile mission has been established based on NGA member input and the Phase I Needs Assessment, and includes the following attributes (beyond those listed in the program requirements):

- (3) plug valves

- (3) back-to-back in-plane 1.5 D 90 degree elbows

- (1) back-to-back out-of-plane 1.5 D 90 degree elbows

- $\quad$ (1) mitered bend (in addition to launch)

- $\quad$ Total elevation change (approx 5 feet per back-back situation): 20 feet

Based on this typical "mission profile", the total energy required to operate the system may be established. The "wild cards" in this analysis are the MFL sensor drag, and the number of 
sweeps required for the MFL sensor to inspect the full pipe circumference. An initial power assessment for a 2.5 mile mission is illustrated in Figure 2 based on a single sensor sweep and a sensor drag of $800 \mathrm{lbs}$. It is clearly demonstrated in the analysis that the sensor, with $800 \mathrm{lbs}$ of drag, demands the majority of the power (65\%). PII is currently working on the MFL sensor development, and will perform physical tests to determine actual sensor drag for a segmented sensor as required to pass a plug valve. The $800 \mathrm{lbs}$ is an estimate from the Phase I program. A key design criterion for the sensor is the reduction of drag. The estimate of 8 battery modules was based on an energy density of 2,500 W hr per battery module.

Total Estimated Battery Capacity for 2.5 Mile Mission with Single Sensor Sweep

\begin{tabular}{|lc|c|c}
\hline \multicolumn{1}{|c|}{ Operational State } & $\begin{array}{c}\text { Power } \\
\text { (watts) }\end{array}$ & $\begin{array}{c}\text { Time } \\
\text { (hr) }\end{array}$ & $\begin{array}{c}\text { Total Energy Required } \\
\text { (W hr) }\end{array}$ \\
\hline Quiescent & 300 & 13 & 3,900 \\
\hline Straight Pipe (MFL on) & 1500 & 8 & $* * 12,000$ \\
Straight Pipe (MFL off) & 500 & 4 & 2,000 \\
Travel in bends (MFL off) & 1400 & .5 & 700 \\
\hline Plug Valves (MFL off) & 500 & .5 & 250 \\
\hline & & & 18,850 \\
\hline
\end{tabular}

\title{
@ 2,500 W hr/module (estimate): 8 modules required
}

\author{
Assumptions: \\ 1. Based on stated mission profile for 2.5 mile inspection \\ 2. $13 \mathrm{hr}$ mission time: $8 \mathrm{hr}$ forward (2.5 miles inspecting), $4 \mathrm{hr}$ return (no inspection), $.5 \mathrm{hr}$ \\ for bends, $.5 \mathrm{hr}$ for plug valves \\ 3. $800 \mathrm{lb}$ sensor drag (approx $1100 \mathrm{~W}$ with additional "overhead") \\ 4. Negligible flow drag (nominal conditions) \\ 5. Bend power includes elevation change (20 feet) @ $2000 \mathrm{lb} \times 30 \mathrm{ft} / \mathrm{min}$ ); neglected power \\ to descend bends
}

\section{Figure 2. Initial power assessment}

A preliminary assessment of battery needs was conducted whereby batteries were packaged within the two optimized volumes for passing through plug valves and miter bends. Commercially available lithium-ion cells were incorporated into each "shape". The battery modules will be further refined as the sensor issues (drag and number of sweeps) become more defined. 


\section{Task 2.1.1.4: Winder Design}

Winder design was initiated and is nearly complete. This design is proprietary to FosterMiller.

\section{Task 2.1.1.5: Module Design}

Effort was just initiated at the end of the reporting period.

\section{Task 2.1.1.6: Sensor Deployment Mechanism Design}

Effort was just initiated at the end of the reporting period.

\section{Task 2.2 Sensor Module}

\section{Task 2.2.1 MFL Sensor System Design}

A brainstorming session was held during PII's June visit to establish the candidate MFL sensor concepts for evaluation going forward. These concepts were developed by FosterMiller and PII during the Phase I NYGAS program. The scores for each concept were established. PII is currently conducting a feasibility assessment on the top 3 candidates.

\section{Task 2.2.3 Ovality Sensor Design}

Based on information from the NGA member companies, dents greater than $2 \%$ of the nominal pipe diameter must be detected for the 12 " to 24 " pipe range. For the nominal design case of 18 inch pipe (+/- 1 pipe size), this translates to a depth resolution of 0.32 inches for the smallest pipe size of 16 inch. Foster-Miller is currently evaluating industrial single point optical displacement sensors that can detect ovality at approximately 6 sweeps per second (circumferential). The choice was made to go with commercially available components (over a custom designed structured light sensor) due to the reduced development time and costs, established calibration procedures, and minimal computer processing/data storage required. A disadvantage to this type of system is its susceptibility to temperature, 
shock and vibration. Other design issues include the need to use small sensors that fit within a minimum package size, the need for pressure housings, and a somewhat challenging mechanical design that must incorporate the sensor and scan mirror. Components are currently being selected, and will be incorporated into the system once the tractor modeling starts (September - October).

\section{Task 2.3 Camera/Illumination Design}

The camera and illumination system will be designed for forward viewing (front and back tractors) with the capability to view the pipe wall if closer visual inspection is desired. The current plan is to have a rotational capability on the camera for turning towards the pipe wall, with the triad providing the other axis of motion to move the camera along the circumference of the pipe wall (pan feature). This approach will simplify the design process by removing one control axis, but the practicality of this approach will need further study depending on the frequency of viewing (power required to move the triad). Foster-Miller recommends that a color camera with a medium resolution of $480 \times 768$ be employed. A sample picture of an internal pipe wall by a camera of this resolution will be submitted to NGA for their approval. A fisheye lens, favored somewhat by NGA members will also be considered. A diode ring light will be needed for wall inspection, with a higher power lighting system required to illuminate the pipe for navigation and longer range observation. This source will have an adjustable power lever to adjust for different pipe diameters and surface conditions, minimizing the drain on the batteries.

The control of the gimbal(s) and the lens will be included in the optical fiber link system. A pressure housing will be designed for the camera and lighting systems. It may be possible to slowly pressurize and depressurize some electronic components to permit their used under ambient conditions. Foster-Miller has collected multiple commercial specifications for lights and cameras, including those for deep sea applications. The decision about which particular systems to incorporate and their specific location on the triad will be made during the tractor modeling portion of the program (September-October). 


\section{Task 4: Communication}

\section{Task 4.1 Tether Assessment}

In the previous reporting period, Foster-Miller identified a "bend-insensitive" fiber manufactured by the Stocker-Yale Company for use in applications where the fiber is wound onto a spool. Stocker-Yale claims that the fiber may be packaged on a spool during operation without the attenuation that other commercially available fibers experience (these fibers are not designed for transmitting in the "wound" state). Until a better fiber is found, the Stocker-Yale product will be specified in the Phase I design. The choice of this fiber will preclude the testing of any other manufacturer's fiber as proposed in the last report. Having found what we believed to be the best commercially available fiber, the next step was to choose an appropriate jacket to protect the fiber under pipeline conditions. A review of commercially available coatings revealed that a Hytrel/Aramid jacket would provide the best strength and abrasion resistance properties.

A 1 kilometer length of a Hytrel/Aramid jacketed fiber of $0.9 \mathrm{~mm}$ OD was purchased from Stocker-Yale, with delivery scheduled for early July. Attenuation tests will be conducted by Stocker-Yale to quantify attenuation when wound on the spooler under a tension of 1 to 2 lbs. Although only $1 \mathrm{~km}$ of fiber will be tested, Stocker-Yale assures us that the attenuation affects are linear, and that the attenuation for 2.5 miles can be extrapolated. Attenuation tests should be completed by the end of July/early August. A sample of Hytrel/Aramid jacketed fiber (non bend-insensitive) was obtained from another manufacturer to measure friction coefficient (previous calculations assumed a value of 0.5 ) and perform a preliminary abrasion test under the maximum flow conditions attainable in the lab $\left(? \mathrm{~V}^{2} / 2=20\right)$.

The test setup for measuring the friction coefficient is shown in Figure 3 . The friction coefficient tests were conducted by looping a section of the Hytrel/Aramid jacketed fiber though 180 degrees of 16 inch steel pipe (same pipe as used in mockup tests), and securing each end of the tether to a plastic cup for accepting weights. Clearance holes were cut in the table under each end of the pipe to allow the tether to pass through freely. A series of 
measurements were made to determine a coefficient of sliding friction by filling one of the cups with a predetermined amount of weight $\left(\mathrm{W}_{1}\right)$, and then adding weight to the other cup $\left(\mathrm{W}_{2}\right)$ until sliding occurred. The coefficient of sliding friction was equal to $\mathrm{W}_{1} / \mathrm{W}_{2}$. The results are shown below in Table 1 .

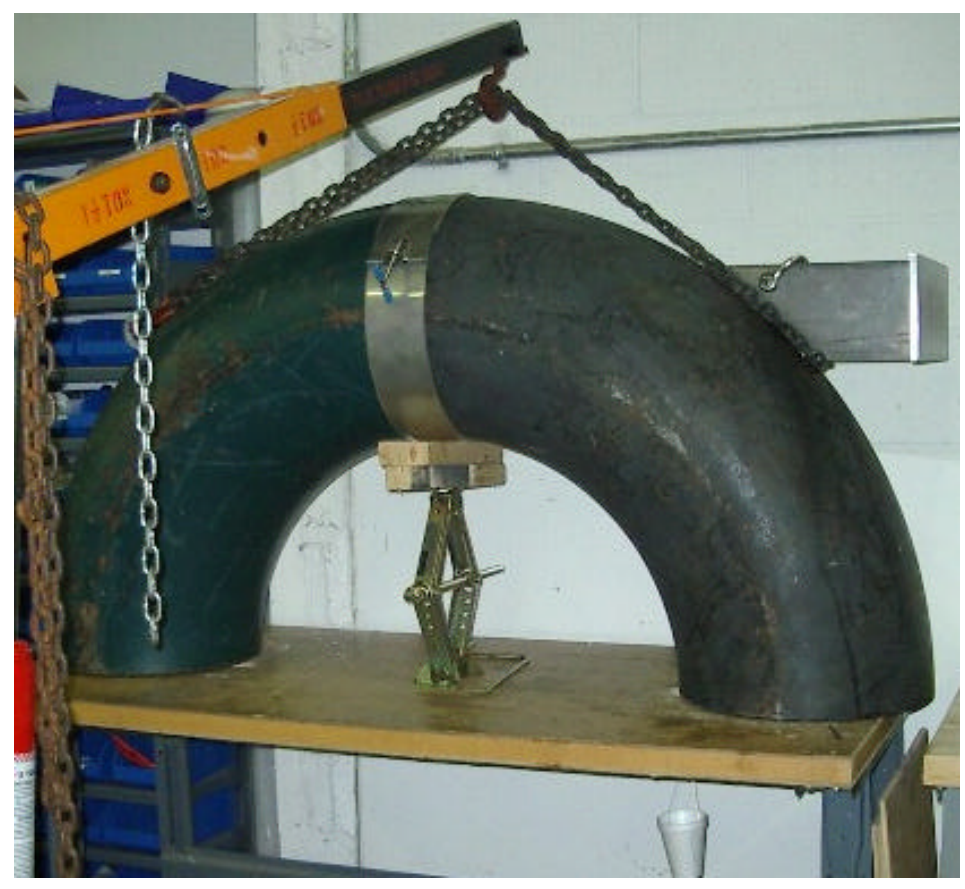

Figure 3. Friction coefficient test setup

Table 1. Coefficient of sliding friction

\begin{tabular}{|c|c|c|}
\hline $\begin{array}{c}\text { W1 } \\
\text { (grams) }\end{array}$ & $\begin{array}{c}\text { W2 } \\
\text { (grams) }\end{array}$ & $\boldsymbol{\mu}$ \\
\hline 14.8 & 38.7 & 0.382 \\
\hline 27.5 & 71.8 & 0.383 \\
\hline 40.1 & 104.9 & 0.382 \\
\hline 53.1 & 141.2 & 0.376 \\
\hline 65.3 & 179.4 & 0.364 \\
\hline 76.8 & 210.9 & 0.364 \\
\hline
\end{tabular}

A somewhat conservative value of 0.37 was chosen, and is reflected in the revised tether flow drag results of Table 2. Table 3 presents the critical values for $? \mathrm{~V}^{2} / 2$ where flow drag and friction drag are equal. As specified in the last report, Foster-Miller recommends that a given tether diameter be used under pipeline conditions only if the tether wall friction is 
greater than the flow drag (until pipeline tests can be performed in later phases of development).

Table 2. Revised flow drag results

\begin{tabular}{|c|c|c|c|c|c|c|c|}
\hline $\begin{array}{l}\text { Velocity } \\
\text { (ft/sec) }\end{array}$ & $\begin{array}{l}\text { Pressure } \\
\text { (psig) }\end{array}$ & $\begin{array}{c}\text { Tether } \\
\text { Diameter } \\
(\mathbf{m m})\end{array}$ & $\begin{array}{c}\text { Fluid Drag } \\
\left(\mathrm{lb}_{\mathrm{f}} \text { per } 1000\right. \\
\text { ft) }\end{array}$ & $\begin{array}{l}\text { Tether Wall } \\
\text { Friction }\left(\mathbf{l b}_{\mathrm{f}}\right. \\
\text { per } 1000 \mathrm{ft})\end{array}$ & $\begin{array}{c}\text { Fluid Drag } \\
\left(\mathrm{lb}_{\mathrm{f}} \text { per }\right. \\
\text { ft) }\end{array}$ & $\begin{array}{l}\text { Tether Wall } \\
\text { Friction }\left(\mathbf{l b}_{\mathrm{f}}\right. \\
\text { per } \underline{2500 \mathrm{ft})}\end{array}$ & $\begin{array}{c}\text { Tether } \\
\text { Strength } \\
\left(\mathrm{lb}_{\mathrm{f}}\right)\end{array}$ \\
\hline \multirow[t]{2}{*}{20} & 350 & $\begin{array}{l}2.9 \\
1.8 \\
1.2 \\
\end{array}$ & $\begin{array}{l}0.66 \\
0.41 \\
0.27 \\
\end{array}$ & $\begin{array}{l}1.94 \\
0.74 \\
0.33 \\
\end{array}$ & $\begin{array}{c}1.65 \\
1.025 \\
0.675 \\
\end{array}$ & $\begin{array}{c}4.85 \\
1.85 \\
0.825 \\
\end{array}$ & $\begin{array}{l}29 \\
16\end{array}$ \\
\hline & & $\begin{array}{c}0.9 \\
0.24\end{array}$ & $\begin{array}{c}0.20 \\
0.055\end{array}$ & $\begin{array}{c}0.22 \\
0.013\end{array}$ & $\begin{array}{c}0.50 \\
0.138\end{array}$ & $\begin{array}{c}0.55 \\
0.033\end{array}$ & \\
\hline \multirow[t]{4}{*}{75} & 1000 & 2.9 & 25.8 & 1.94 & 64.5 & 4.85 & 29 \\
\hline & & $\begin{array}{l}1.8 \\
1.2\end{array}$ & $\begin{array}{l}16.0 \\
10.7\end{array}$ & $\begin{array}{l}0.74 \\
0.33\end{array}$ & $\begin{array}{c}40.0 \\
26.75\end{array}$ & $\begin{array}{c}1.85 \\
0.825\end{array}$ & 16 \\
\hline & & 0.9 & 8.0 & 0.22 & 20.0 & 0.55 & \\
\hline & & 0.24 & 2.14 & 0.013 & 5.35 & 0.033 & \\
\hline \multirow[t]{4}{*}{10} & 250 & 2.9 & 0.12 & 1.94 & 0.30 & 4.85 & 29 \\
\hline & & 1.8 & 0.074 & 0.74 & 0.185 & 1.85 & 16 \\
\hline & & $\begin{array}{l}1.2 \\
0.9 \\
\end{array}$ & $\begin{array}{l}0.049 \\
0.037 \\
\end{array}$ & $\begin{array}{l}0.33 \\
0.22 \\
\end{array}$ & $\begin{array}{l}0.123 \\
0.093 \\
\end{array}$ & $\begin{array}{c}0.825 \\
0.55 \\
\end{array}$ & \\
\hline & & 0.24 & 0.010 & 0.013 & 0.025 & 0.033 & \\
\hline
\end{tabular}

Table 3. Critical Values for $? V^{2} / 2$ Where Tether Wall Friction is Equal to Fluid Drag

\begin{tabular}{|l|l|}
\hline Tether Diameter $(\mathbf{m m})$ & $\begin{array}{l}\text { Critical } \mathbf{~ V}^{2} \mathbf{2} \\
\left(\mathbf{l b}_{\mathbf{f}} / \mathbf{f t}^{\mathbf{2}}\right)\end{array}$ \\
\hline 2.9 & 16 \\
\hline 1.8 & 10 \\
\hline 1.2 & 7 \\
\hline 0.9 & 6 \\
\hline 0.24 & 1 \\
\hline
\end{tabular}

A photograph of the mitered corner abrasion test is shown in Figure 4. The Hytrel/Aramid jacketed fiber (non-bend-insensitive) was tested under the maximum laboratory flow conditions of $? \mathrm{~V}^{2} / 2\left(\mathrm{lb}_{\mathrm{f}} / \mathrm{ft}^{2}\right)=20$ under the worst-case test conditions of a sharp mitered- 
corner bend with the tether oscillating under no tension. The mitered elbow was manufactured at Foster-Miller, with the joint left in the "as manufactured" conditions (sharp edges and weld debris maintained). After 12 hours of testing, a "flattening" of the tether occurred in the area where it contacted corner of pipe, but no abrasions or cuts in the jacketing were evident. Unfortunately, this was not a bend-insensitive fiber, so there was no value in measuring attenuation. The test will be repeated once the bend-insensitive cable purchase from Stocker-Yale is back from lab testing (attenuation). In the meantime, other material options for the outer jacket will be evaluated. It should be noted that this is only an issue if mitered corners are in system (no other sharp edges have been identified in the NGA transmission pipe system)

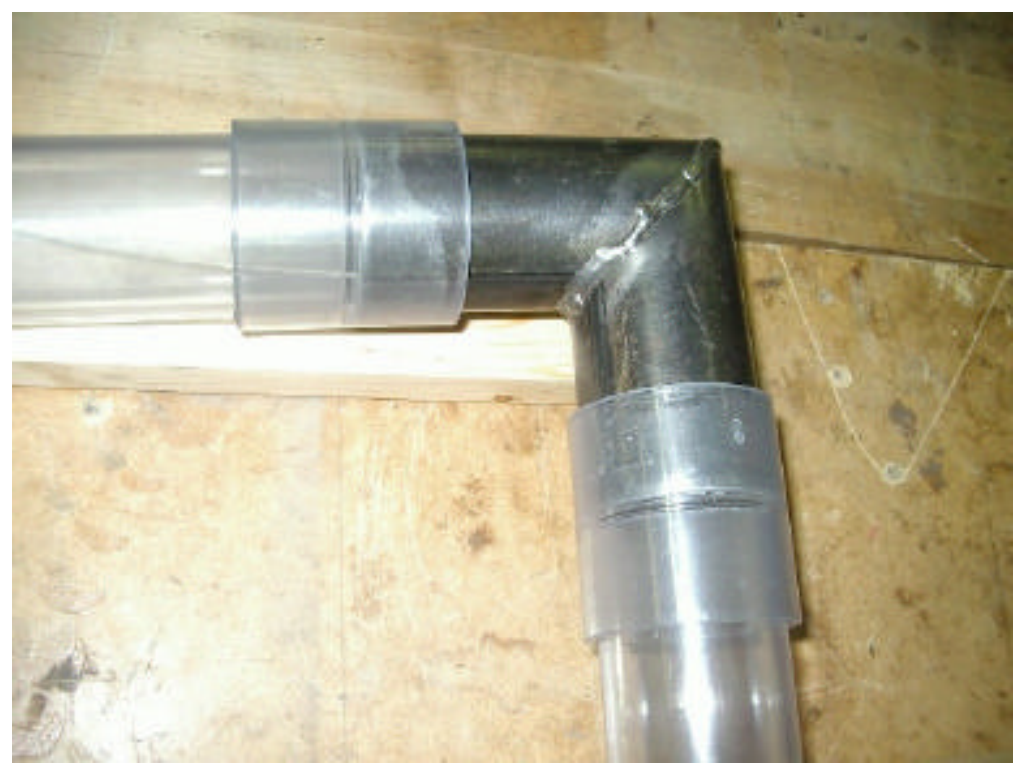

\section{Figure 4. Tether abrasion test in mitered corner}

A winder module for the 18 inch nominal system (16 in to 20 in range) has been designed for packaging the $0.9 \mathrm{~mm}$ fiber. This design is based on the winder module employed in the GRI Pipe Mouse. The function of the winder module is to manage the payout and retrieval as the 
platform moves in the pipe. The tether provides for 2-way communication between the platform and the control station. Operator control is communicated to the robot, while MFL sensor, control sensor and video data are transmitted back to the control station. An electric to fiber optic conversion takes place within the spool. The fiber is wound onto the spool, which is rotated by a single back-drivable brushless DC motor. A cable guide system is used to precisely wind the fiber onto the spool. An accumulator system is used to maintain a constant tension in the tether during pay out and collection, and provide a system buffer to compensate for any time delays in motor or processor time so as not to exceed the prescribed tension. The tension must be sufficient to maintain an adequate packing density in the winder, while not increasing attenuation in the transmitted signal. A tension of 1 to 2 lbs. will be maintained by the accumulator.

It is critical that dirt and debris are prevented from entering the winder module. Two potential tether cleaning concepts are currently being considered. 
PROJECT STATUS BY TASK (as per June 30,2003$)^{1}$

Task 1: Program Management

On-going

Task 1.1: Research mangement Plan

Completed

Task 1.1.1: Requirements Document

Completed

Task 1.2 Technology Assessment

Completed

Task 1.3 Technical Oversight

On-going

Task 2: Mechanical Design: Robotic Platform and Sensor Module

On-going

Task 2.1: Robotic Platform

On-going

Task 2.1.1: Systems Engineering

On-going

Task 2.1.1.1: Kinematics Analysis

On-going

Task 2.1.1.2: Brainstorming Session

Completed

Task 2.1.1.3: Tractor Design

Initiated

Task 2.1.1.4: Winder Design

Initiated

Task 2.1.1.5: Module Design

Initiated

Task 2.1.1.6: Sensor Deployment Mechanism Design

Initiated

Task 2.1.1.7: System Integration

Not Initiated

Task 2.2: Sensor Module

Initiated

Task 2.2.1: MFL Sensor System Design

Initiated

Task 2.2.2: Module Design Support

Initiated

Task 2.2.3: Specify Ovality Sensor

Initiated

Task 2.3: Specify Camera/Illumination

Initiated

Task 3: Eletrical/Control Design

Initiated

Task 4: Communication

On-going

Task 4.1 Tether Assessment

On-going

Task 4.1.1: Analysis

Completed

Task 4.1.2: Choose/procure candidate materials

Completed

Task 4.1.3: Test Plan

Completed

Task 4.1.4: Lab Test

On-going

Task 4.1.5: Tether Test Report

Initiated

Task 4.2 Specify Communication Components

Not Initiated

Task 5: Auxiliary Components

Not Initiated

Task 6: Management and Reporting

On-going

\footnotetext{
${ }^{1}$ Items indicated in bold were initiated during this reporting period
} 


\section{RESULTS AND DISCUSSION}

Tether assessment is nearly complete. Results indicate that the tether option is viable in the case of low and moderate transmission pipeline pressures and flows. Final studies and testing are underway to determine the abrasion characteristics of the tether under various flow conditions. Winder design is in progress while two options are considered regarding tether cleaning.

Sensor design was initiated following the signing of the collaborative agreement between Foster-Miller and PII. A brainstorming session was held to revisit the concepts developed in the earlier Phase I of this work (not funded by DoE) and potentially develop new ones. PII is now in the process of selecting the one design to be integrated in the robotic platform.

The kinematics testing in the mockup built in the laboratory is in progress and should be completed by the first week of August, 2003.

The camera and illumination system will be designed for forward viewing (front and back tractors) with the capability to view the pipe wall, if closer visual inspection is desired.

Regarding the ovality sensor, the choice was made to adopt a commercially available light sensor, due to the reduced development time and costs, established calibration procedures, and minimal computer processing/data storage required. 


\section{CONCLUSION}

The project is progressing rapidly in all fronts, i.e. platform design, sensor design, and tether evaluation.

The agreement between Foster-Miller and PII has been signed and a kickoff meeting between the two parties took place in late June 2003.

The tether option appears to be viable for low and medium pipeline pressures and flows. Advanced tether coating options are being explored that will minimize tether abrasion problems.

The camera/illumination system and ovality sensor efforts have been initiated and the basic technology/options to be used for each have been selected. 


\section{REFERENCES}

None. 